\title{
Interdisciplina e Intersectorialidad
}

\author{
Interdiscipline and intersectoriality
}

Cada día se hace más evidente la necesidad de realizar las tareas de la salud pública con un enfoque interdisciplinario e intersectorial. En ese sentido se ha conducido el pensamiento de nuestra Escuela de Salud Pública. Las páginas de esta revista se han hecho eco de este pensamiento.

Sin embargo no se ha alcanzado hoy la unidad de pensamiento en la dirección indicada, lo que provoca análisis y enfoques desacertados sobre numerosos problemas de salud.

Un área sensible frente a este problema es la educación para la salud. Sin la comprensión y actuación consecuente no pueden colocarse los mensajes de nuestros medios de comunicación masiva (televisión, radio y prensa plana) en la posición de participante activa en la tarea de hacer en esos medios un efectivo trabajo de educación para la salud, lo que se produce es de perfil escolástico, repetitivo, contradice la esencia de una buena educación sanitaria. Resultado magro, por ej. en la lucha contra el tabaquismo. Solo una estrecha cooperación entre los medios mencionados y las instituciones del sector de la salud puede lograr rectificar la situación descrita. Y esta concepción intersectorial del trabajo, pasa por la obligatoria interdisciplinaridad, donde junto a periodistas y otros comunicadores sociales, estén los antropólogos, sociólogos, psicólogos, médicos de distintas especialidades, y otros, tantos como fuera necesario.

Los asuntos de la salud human han estado por muchos siglos en manos (y cabezas) de la profesión médica que han sido hegemónica y celosa cuidadora de las prerrogativas que la sociedad les daba. Esto ha estado cambiando en las últimas décadas. Lentamente. Pero ya no es prohibido abrir a la discusión entre personas e instituciones el problema que estamos observando. Ya son numerosos los médicos e instituciones del sector de la salud que aceptan la participación de otros en la búsqueda de soluciones a problemas, que se llaman de la salud o médicos, pero que son de todos. Recuérdese lo relativo a la "epidemia de obesidad", que se extiende por el mundo. ¿Quién tiene la solución?

Una contribución especial para el avance de estas ideas de integración radica en el trabajo de los centros formadores de los profesionales de la salud, desde el pregrado hasta el más alto posgrado. Lo mismo debe promoverse en los del "otro lado".

http://scielo.sld.cu 
De una adecuada relación entre los factores mencionados se puede obtener resultados beneficiosos para la población, de efectos más extensos y profundos que alguna de las novedosas tecnologías que reciben atención exagerada cuando de ellas tratan en los "medios".

Los que se detengan a reflexionar sobre este asunto, acérquense a la búsqueda de la respuesta a estas preguntas (sólo 3):

¿Cómo detener el progreso de la epidemia de Sida?

¿Cómo reducir hasta la eliminación la frecuencia Del Alcoholismo?

¿Cómo elevar la conciencia social hasta lograr una conducta colectiva protectora de la higiene ambiental? 